\title{
A inclusão de alunos com necessidades educativas especiais: um desafio para a universidade
}

\section{The inclusion of students with special educational needs: a challenge for the university}

La inclusión de alunos con necesidades educativas especiales: un desafío para la universidad

Marcos Vinicius Dimas Pacifico ${ }^{1}$ Nayara da Silva Cesario Martins ${ }^{2}$

${ }^{1}$ Licenciado em Química pelo Instituto Federal Goiano Campus Ceres. Pós-graduado lato sensu em Docência no Ensino Superior pela Universidade Católica Dom Bosco (UCDB). E-mail: marcos-dipa@hotmail.com

${ }^{2}$ Graduada em Fonoaudiologia pela Universidade Católica Dom Bosco (UCDB). Pós-graduada em Educação Especial (com ênfase ao atendimento pedagógico para a inclusão escolar). Pós-graduada em Língua Brasileira de Sinais. Mestre em Educação (UCDB). E-mail: nayara.cesario@hotmail.com 
Resumo: inclusão na universidade é um direito de acadêmicos com necessidades educativas especiais, garantindo uma educação de qualidade a todos. Delinear-lhes os obstáculos para tal inclusão se configura como principal objetivo deste trabalho, que é descritivo de caráter exploratório, qualitativo, realizado por revisão bibliográfica, buscando artigos na Biblioteca Virtual de Saúde (BVS), com base de dados na Literatura Latino-Americana e do Caribe em Ciências da Saúde (LILACS), artigos em português, de 2005 e 2015, relacionados à questão norteadora. Essa inclusão implica desafios, destacando-se: barreiras arquitetônicas, falta de recursos adequados às necessidades educacionais, despreparo e dificuldades dos professores em promover e lidar com a inclusão, além das principais medidas realizadas para incluí-los na universidade. Assim, ao iniciar a vida na universidade para esses acadêmicos, evidencia-se a necessidade de uma diversidade de aperfeiçoamento como em estruturas físicas, elaboração curricular direcionada, formação curricular dos professores e inserção de tecnologias assistivas.

Palavras-chave: inclusão social; necessidades especiais; universidade.

\begin{abstract}
The inclusion in the university is a right of students with special educational needs ensuring quality education to all. Outlining the obstacles for such inclusion sets up as the primary objective of this work, that is a descriptive of exploratory character, qualitative, conducted through literature review, searching articles published in the Virtual Health Library (VHL), whose database the Latin America and Caribbean Literature in Health Sciences (LILACS), articles published in Portuguese from 2005 and 2015 related to guiding question. This inclusion implies challenges, highlighting: architectural barriers, lack of adequate resources to meet the educational needs, lack of preparation and the difficulties of teachers to promote and deal with their inclusion besides the principal measures taken to the inclusion in the university. Like this, to begin life at the university to these students, highlights the need for improvement in all prisms of the university as in physical structures, development of targeted curriculum subjects, improvement of curriculum training for teachers and the inclusion of assistive technologies.
\end{abstract}

Key words: academic inclusion; special needs; university.

Resumen: La inclusión en la universidad es un derecho de los estudiantes con necesidades educativas especiales asegurando una educación de calidad para todos. Contornar los obstáculos en tal inclusión se configura como el principal objetivo de este trabajo, que es descriptivo de carácter exploratorio, cualitativo, realizado a través de la revisión de la literatura, en busca de artículos publicados en la Biblioteca Virtual en Salud (BVS), con la base de datos de la Literatura Latinoamericana y del Caribe en Ciencias de la Salud (LILACS), artículos publicados en la lengua portuguesa en el periodo de 2005 y 2015, relativos con la cuestión principal. Esa inclusión implica desafíos, destacándose: barreras arquitectónicas, falta de recursos adecuados para satisfacer las necesidades de educación, falta de preparación y las dificultades del profesorado en promover y hacer frente a la inclusión, además de las principales medidas adoptadas para la inclusión en la universidad. Así, al iniciar la vida académica de estos estudiantes, se evidencia la necesidad de una diversidad de perfeccionamiento en estructuras físicas, desarrollo de las materias curriculares específicas, mejora de los programas de capacitación de maestros y la inclusión de tecnologías de asistencia.

Palabras clave: inclusión social; necesidades especiales; universidad. 
A inclusão de alunos com necessidades educativas especiais: um desafio para a universidade

\section{INTRODUÇÃO}

Conforme o último censo do Instituto Brasileiro de Geografia e Estatística (IBGE) realizado, a pesquisa em 2010 revela que, no Brasil, existem 45,6 milhões de pessoas com algum tipo de deficiência, dentre eles vários estão ingressando em universidades, buscando seu direito de inclusão social através da busca pelo conhecimento.

Os desafios da inclusão dos acadêmicos com necessidades educativas especiais se tornam os principais obstáculos que eles próprios enfrentam ao iniciarem a vida acadêmica na universidade, onde muitas vezes são colocados frente a frente a vários desafios. Onde muitas vezes Ihes é negado ou negligenciado o apoio pedagógico necessário a uma formação acadêmica e profissional que atinja os limites das suas necessidades educacionais especiais.

A inclusão de alunos com necessidades especiais na universidade é uma problemática pouco discutida e pesquisada no Brasil. Diante disso, ela traz consigo o desafio não só de acolhimento destes acadêmicos, envolvendo ainda as condições de acesso e de aprendizagem em todos os espaços, bem como os programas e as atividades desenvolvidas no âmbito universitário. Por isso, o atendimento educacional especializado deve aparecer como uma garantia de inclusão que propicie a esses acadêmicos serem atuantes no processo de desenvolvimento e de aquisição do conhecimento.

Diante desse contexto social e educacional, torna-se indispensável para os educadores e para toda a comunidade universitária refletir sobre: Quais são os obstáculos que dificultam o processo ensino-aprendizagem bem como a inclusão dos acadêmicos com necessidades educativas especiais no ambiente universitário? Quais são as medidas fundamentais a serem tomadas pelas universidades para promover de inclusão desses acadêmicos? As oportunidades de atendimento especializado no espaço universitário estão em consonância com a LDBEN, decretos e políticas de educação inclusiva? 
A presente pesquisa trata-se de um estudo de revisão bibliográfica, descritivo com análise sistemática e qualitativa, tendo como proposta de investigação: "Os desafios enfrentados pela universidade na inclusão dos acadêmicos com necessidades especiais". Esta pesquisa foi realizada por meio da busca de artigos publicados na Biblioteca Virtual de Saúde (BVS), tendo como base de dados a Literatura Latino-Americana e do Caribe em Ciências da Saúde (LILACS), artigos publicados na língua portuguesa no período de 2005 e 2015 relacionados à questão norteadora, considerando as seguintes palavras-chaves de forma combinada: inclusão acadêmica, necessidades especiais, universidade. Os critérios usados na seleção dos materiais de pesquisa foram: artigos completos, em língua portuguesa, relacionados com o assunto proposto, bem como monografias, dissertações e livros (integralmente ou parcialmente), leis e decretos, sendo que foram excluídos: artigos incompletos, que se encontraram fora da base de dados mencionada ou que não atenderam ao tema proposto. Quanto às fontes de pesquisa, houve algumas limitações, pois as leis e os decretos não trazem nenhuma alusão ao acesso de acadêmicos com necessidades educacionais especiais no ensino superior de forma específica. As referências são sempre mais genéricas ou mais específicas para a educação básica, especialmente para a educação infantil e o ensino fundamental.

Com base nessas fontes de pesquisa, foram expostas e confrontadas as ideias dos diversos autores, dentre os quais podemos mencionar: Cunha e Carrilho (2005), Figueiredo (2008), Haiduke e Alcântara (2007), Leite (2011), Leão (2004), Masini (2010), Martins (2008), Moraes (2007), Nascimento (2009), Vitaliano (2007) entre outros, permitindo assim a construção de uma perspectiva que foi apresentada no momento das considerações finais.

Portanto o presente trabalho teve como principal objetivo delinear os obstáculos no processo de inclusão dos acadêmicos 
A inclusão de alunos com necessidades educativas especiais: um desafio para a universidade

com necessidades educacionais especiais no ambiente universitário, citando as principais dificuldades que os professores enfrentam em relação a essa inclusão, evidenciando medidas fundamentais para a inclusão desses acadêmicos e descrevendo as perspectivas da educação inclusiva para eles.

\section{EDUCAÇÃO INCLUSIVA NO BRASIL: UMA ANÁLISE HISTÓRICA-EVOLUTIVA ATÉ OS DIAS ATUAIS}

As necessidades especiais podem ser consideradas deficiências que ocasionam numa perda ou anormalidade de uma estrutura ou função corporal, que, muitas vezes, torna-se uma incapacidade de desenvolver certas atividades normais com habilidade. Os tipos de deficiência são classificados conforme suas limitações em: deficiência auditiva, física, mental, visual e múltipla (BRASIL, 2004; REBOUÇAS et al., 2011).

A inclusão é um direito que deve ser assegurado a todas as pessoas, permitindo assim a inserção das pessoas com necessidades educacionais especiais independente das suas limitações, das suas dificuldades ou das suas condições no cotidiano social e educacional, sendo que essas pessoas também são consideradas cidadãos e integrantes de uma sociedade que deve estar preparada e orientada para lidar com as diversidades humanas e com a aceitação das diferenças (LEÃO, 2004; MAIOLA; BOOS; FISCHER, 2008; DUARTE et al., 2013). Como as pessoas são diferentes, elas também aprendem de modo peculiar. Dessa forma, fica difícil para o aluno progredir na sua aprendizagem quando suas necessidades deixam de ser atendidas ou quando não recebe por parte da própria universidade, o atendimento especial que espera para se sentir seguro e confiante nesse processo de busca do conhecimento.

Rocha e Miranda (2009) afirmaram que a inclusão social é um fator fundamental que contribui para o desenvolvimento de uma 
sociedade, que deve adaptar-se às necessidades especiais das pessoas, o que pode ser feito por pequenas ou grandes transformações realizadas nos ambientes físicos através da utilização de diversas tecnologias assistivas e equipamentos. Além disso, é necessário que haja o apoio da família, dos amigos e da própria sociedade, principalmente com respeito e aceitação às diferenças.

De acordo com França, Pagliuca e Baptista (2008), a inclusão social é uma forma de controle da exclusão que acontece dentro da sociedade e, geralmente, essa exclusão está intimamente ligada às pessoas com padrões financeiros insuficientes e às pessoas com necessidades especiais como as deficiências auditiva, física, mental, visual ou múltipla.

Considerando o panorama histórico da educação inclusiva no Brasil, Mendes (2010) mencionou que a educação inclusiva no Brasil foi estabelecida no final do século XIX, com base nas experiências da Europa, porém a inserção da educação inclusiva brasileira ocorreu somente no fim dos anos 50. Nessa mesma abordagem, Réus e Cavalari (2010) afirmaram que a evolução da educação inclusiva brasileira ocorreu em vários períodos: até 1954, as pessoas com necessidades educacionais especiais eram excluídas da família e da sociedade, sendo acolhidas em asilos e instituições religiosas ou filantrópicas que posteriormente surgiriam como escolas com atendimento especial para esses indivíduos. No período de 1954 a 1956, surgiram algumas escolas com atendimento especial para essas pessoas; o período de 1957 a 1993 foi marcado por ações voltadas para o atendimento educacional por meio de campanhas de educação e reabilitação em prol dessas pessoas deficientes em âmbito nacional.

Em 1994, houve a participação do Brasil na Conferência Mundial sobre as Necessidades Educacionais Especiais na Espanha, estabelecendo assim a política de educação inclusiva. Nessa conferência, o Brasil junto com outros países assinaram a Declaração de Salamanca, 
A inclusão de alunos com necessidades educativas especiais: um desafio para a universidade

que consistiu em um documento de compromisso de garantia de acesso das pessoas com necessidades especiais a condições educacionais especiais, além do direito de educação a todos (PACHECO; COSTAS, 2006; RODRIGUES; MARANHE, 2008). Em 1996, houve a criação da Lei n. 9.394, que estabeleceu a Lei de Diretrizes e Bases da Educação Nacional (LDBEN), cujo objetivo foi oferecer educação de qualidade a todas pessoas, dando oportunidades de atendimento especializado na rede regular de ensino às pessoas com necessidades especiais (BRASIL, 1996).

Segundo Leão e Costa (2005), a educação inclusiva é uma prática de inclusão de todos acadêmicos que possuem algum tipo de necessidade especial educativa no espaço universitário, os quais devem ter o direito a uma educação de qualidade a ser oferecida de forma adequada. Além disso, precisa-se de diversos recursos qualificados e do apoio da sociedade, para que haja o desenvolvimento da aprendizagem e das habilidades referentes aos conteúdos acadêmicos ministrados.

Siqueira e Santana (2010) corroboraram que a inclusão na universidade é um direito que deve ser assegurado a todos acadêmicos com necessidades educativas especiais, que devem ter acesso garantido a uma educação de qualidade, com a adaptação de ambientes físicos, com a adequação de recursos e materiais adequados, além do apoio pedagógico necessário para sua formação acadêmica de qualidade.

Conforme o Censo da Educação Superior, Ministério da Educação (MEC), Instituto Nacional de Estudos e Pesquisas Educacionais (INEP) (BRASIL, 2012), havia, nesse ano, 22.455 matrículas de alunos com deficiência no ensino superior, sendo desse total, 16.790 nas Instituições Privadas de Ensino Superior e 5.665 nas Instituições Federais de Ensino Superior. O número de acadêmicos com deficiência tem aumentado no ensino superior, embora de modo bem tímido, principalmente a 
partir de 2000, quando o MEC passou a considerar a infraestrutura oferecida a esses alunos, refletindo positivamente ou não nos conceitos atribuídos aos cursos superiores. Porém esse número ainda é pequeno em relação ao atendimento que se realiza na educação básica, na qual existe suporte maior de acolhida e de atendimento, fruto da mobilização de educadores e da própria sociedade civil. Esse processo precisa se estender também para o ensino superior. Também é possível perceber a crescente participação das pessoas com necessidades especiais no mercado de trabalho.

Os universitários com necessidades educativas especiais, ao iniciarem a vida acadêmica, são colocados frente a vários desafios relacionados ao acolhimento em todos os espaços, envolvendo quase sempre a dificuldade nas adaptações dos ambientes físicos, inadequação e ausência de recursos didático-pedagógicos e a falta de conhecimentos e o despreparo dos professores para lidar com esses acadêmicos, independente de suas necessidades educativas especiais (HAIDUKE; ALCÂNTARA, 2007).

De acordo com Pacheco e Costas (2006), para que a inclusão dos acadêmicos com necessidades educacionais especiais seja eficiente, devem ser introduzidas na universidade medidas fundamentais que facilitem e, ao mesmo tempo, procurem auxílio na concretização desse processo de inclusão, em que se pode assim destacar: a formação de professores, a adequação de recursos pedagógicos, a adaptação de currículos para o processo educativo e as adaptações nas estruturas físicas.

\section{DESAFIOS DA ACESSIBILIDADE DOS ACADÊMICOS COM NECESSIDADES EDUCACIONAIS ESPECIAIS}

A inclusão traz consigo alguns desafios para o processo de engajamento de acadêmicos com necessidades educacionais especiais 
A inclusão de alunos com necessidades educativas especiais: um desafio para a universidade

na universidade, entre eles pode-se destacar: a presença de barreiras arquitetônicas; a falta de recursos adequados para atender às necessidades educacionais especiais desses acadêmicos e o despreparo dos professores (PACHECO; COSTAS, 2006; HAIDUKE; ALCÂNTARA, 2007).

Haiduke e Alcântara (2007) mencionaram que a presença de barreiras arquitetônicas são problemas impostos na condição da estrutura física, tendo grande influência na vida dos acadêmicos com necessidades educativas especiais dentro da universidade, onde quase sempre os ambientes estão inadequados e não estão preparados para receber esses acadêmicos.

Nesse sentido, Lopes e Marquezine (2012) afirmaram que a maioria das instituições de ensino superior parece não estar preparada, nem estruturada para incluir os acadêmicos com necessidades especiais e oferecer o atendimento adequado a essa nova realidade.

Moraes (2007) e Maiola, Boos e Fischer (2008) apontaram que as adaptações arquitetônicas ocorrem depois de grande parte das instituições de ensino superior já terem sido construídas, sendo que ainda precisam adequar-se às condições de segurança eliminando assim o máximo de barreiras presentes em todos os espaços conforme surgem as necessidades dos acadêmicos com deficiência. Porém os problemas arquitetônicos não estão somente na construção das instituições, mas na realização de novas adaptações necessárias nas estruturas físicas.

Baseado nisso, Miranda e Galvão Filho (2012) confirmaram que essas barreiras arquitetônicas impedem o livre acesso dos acadêmicos com necessidades especiais em diversos espaços, devido à falta de rampas, de banheiros adaptados, de pisos antiderrapantes com desníveis, sem rebaixamento de meio fio; escadas com degraus altos, sem presença de corrimão; orelhões em área de circulação sem a devida sinalização tátil, equipamentos em alturas inacessíveis para todos acadêmicos, incluindo os cadeirantes; a falta de vagas 
nos estacionamentos para os acadêmicos com deficiência, em locais importantes como biblioteca, reitoria, restaurante universitário entres outros.

Ainda, Miranda e Galvão Filho (2012) afirmaram que as instituições de ensino não têm condições adequadas em alguns ambientes devido à presença de barreiras arquitetônicas, mas que a dificuldade da inclusão vai além da estrutura física, sendo que a maioria das instituições não dispõe de materiais e recursos didático-pedagógicos adequados para atender às necessidades educacionais especiais dos acadêmicos.

No mesmo intuito da inclusão, os recursos e as tecnologias assistivas para a educação inclusiva ainda não estão disponíveis em todas as instituições de ensino superior e, quando há a disponibilidade de tais recursos, nem todos os professores os conhecem ou sabem fazer uso destes em sala de aula (GASPARETTO et al., 2009).

Os autores mencionaram que alguns professores atuantes no contexto da educação inclusiva possuem alguns materiais adaptados para atender estses acadêmicos, mas há ainda o desconhecimento na forma de utilizá-los (DE VITTA; DE VITTA; MONTEIRO, 2010).

$E$ isto se torna também um desafio não só para esses acadêmicos, mas para todos aqueles que com estes trabalham, devido à ausência de recursos para o processo de ensino-aprendizagem, à falta de orientações sobre os tipos de deficiências e as possibilidades de aprendizado desses acadêmicos, à falta de conhecimento dos professores sobre os procedimentos de atenção a eles, nos quais muitas vezes conduzem de forma inadequada o método de ensino (MASINI, 2010).

Além disso, os professores, em sua maioria, relatam o receio antes mesmo de lidar com a inclusão, devido à própria falta de preparo, mesmo assim os professores entendem a necessidade em atender os acadêmicos com deficiência, mesmo quando eles não se sentem 
A inclusão de alunos com necessidades educativas especiais: um desafio para a universidade

preparados e orientados para acolherem esses acadêmicos (PACHECO; COSTAS, 2006; MIRANDA; GALVÃO FILHO, 2012).

Vitaliano (2007) reitera que existem professores despreparados devido à inexperiência de ensinar e à falta de conhecimentos específicos suficientes para atuarem no processo de inclusão dos alunos em todos os níveis de ensino. Os professores não estão preparados, porque alguns deles não tiveram uma disciplina específica que pudesse auxiliar em sua prática pedagógica; os que tiveram essa disciplina, afirmaram que os conteúdos estudados não foram suficientes, somados à falta de uma oportunidade de estágio em sala de aulas com acadêmicos com necessidades especiais.

A própria formação dos professores que atuam no processo de inclusão pode tornar-se também um dos desafios enfrentados pelos acadêmicos com necessidades educativas especiais. Isso está relacionado ao despreparo dos professores que, quando se deparam em sua prática pedagógica com esses acadêmicos, não sabem lidar em sala de aula com as diferenças que podem ser cognitivas, sensoriais e físicas, isso acaba interferindo no aprendizado dos acadêmicos com deficiência (VITALIANO, 2007; MONTEIRO; MANZINI, 2008; GIROTO; CASTRO, 2011; MICHELS, 2011). Por outro lado, deve observar-se que a questão fundamental para assegurar a permanência do aluno com deficiência no contexto educacional superior não é uma tarefa única e exclusiva dos professores, que, muitas vezes, têm que trabaIhar com um único plano de aula para lidar com a diversidade, em que todos os alunos são diferentes, mas sim uma tarefa conjunta da comunidade acadêmica, envolvendo professores, fonoaudiólogos, psicólogos, alunos, funcionários, corpo diretivo e atendimento educacional especializado. Ademais, indispensável o apoio das famílias desses acadêmicos, que muitas vezes, por desconhecer o direito da inclusão, impedem que estes ingressem na universidade e conquistem espaço no mercado de trabalho. 
Além disso, a universidade tem o papel de garantir que as condições de acesso e de permanência dos universitários com necessidades educacionais especiais sejam uma realidade, e não simplesmente um direito camuflado e negligenciado, como muitas vezes é visto nos vários setores da sociedade (educação, saúde, transporte público etc.), nos quais as pessoas com necessidades especiais sofrem pela falta de qualidade de atendimento nos diversos serviços à população.

Outros desafios enfrentados pelos acadêmicos com necessidades especiais inerentes à universidade estão relacionados à existência de qualquer tipo de discriminação, de preconceito, de obstáculos e de barreiras que são impostas por diferentes segmentos em relação ao respeito e à igualdade em sala de aula, o que faz com quem esses alunos se sintam desvalorizados e desmotivados; também existe a questão da ausência de recursos humanos que envolvem uma rede de apoio com profissionais especializados (psicólogos, psicopedagogos, fonoaudiólogos etc.) voltados para atender esses acadêmicos, tendo isso influência no processo de ensino-aprendizagem (PERINI, 2006; ANJOS; ANDRADE; PEREIRA, 2009; MIRANDA; GALVÃO FILHO, 2012).

Nesse mesmo intuito da inclusão, Briant e Oliver (2012) afirmaram que ainda há muitas dificuldades por parte dos professores quando têm que receber os acadêmicos com necessidades especiais, pois a maioria deles apresentam dificuldades em acompanhar e transmitir o conteúdo ministrado e também não conseguem desenvolver certas atividades com esses acadêmicos.

Em virtude do despreparo dos professores, a maioria deles apresenta dificuldades em promover a inclusão desses acadêmicos, antes mesmo de conhecer a realidade de cada acadêmico e de ter o primeiro contato direto com eles dentro da sala de aula, pois não sabem como lidar com essa situação, culminando aos professores o sentimento de impotência, de frustração e de choque, ao iniciarem seu trabalho com os acadêmicos com necessidades educacionais especiais, sendo 
A inclusão de alunos com necessidades educativas especiais: um desafio para a universidade

que eles percebem um grande vazio em sua formação, seja pela falta de treinamento, seja pela falta de conhecimentos específicos, tendo tudo isso grande influência em desenvolver um trabalho com qualidade (VITALIANO, 2007; ANJOS; ANDRADE; PEREIRA, 2009; BRIANT; OLIVER, 2012; TOLEDO; VITALIANO, 2012).

Diante de todos os desafios enfrentados em relação à inclusão dos acadêmicos com necessidades especiais na universidade, não se pode esquecer de tomar decisões sensatas e coerentes, as quais devem contar com vários apoios necessários, incluindo também algumas medidas fundamentais que facilitem o processo de inclusão, sendo garantido o acesso a um ensino de qualidade. Ao contrário do que acontece muitas vezes, quando se nega o apoio pedagógico necessário para uma formação profissional que atinja os limites das necessidades educacionais especiais desses acadêmicos (PACHECO; COSTAS, 2006; DUARTE et al., 2013).

Na concepção de Nascimento (2009), uma das medidas mais importantes para a inclusão dos acadêmicos com necessidades especiais no ambiente universitário pode estar relacionada ao professor que atua na educação inclusiva, pois este precisa estar muito bem preparado em seu processo de formação para atender os acadêmicos com necessidades educativas especiais, em que lhe cabe a função de organizar suas ações pedagógicas, então voltadas para as necessidades especiais desses acadêmicos em sala de aula.

Melo e Pereira (2013) mencionaram que os professores são considerados como os principais responsáveis pelo processo de inclusão. Assim torna-se necessário estarem eles bem preparados para atuar junto a esses acadêmicos, por terem de identificar e saber intervir em situações e em atividades que privilegiem as necessidades educacionais especiais de cada acadêmico.

Ademais, esses profissionais devem apresentar uma formação teórica e prática acopladas à realidade social, que deve ser um dos 
fatores mais importantes para a construção de uma nova prática pedagógica. Os autores ainda corroboram que uma formação construída nesse método representa também um dos fatores mais importantes e indispensáveis para que os professores não se sintam angustiados e inseguros, e possam afastar de si mesmos o sentimento de impotência, de frustração e estado de choque e de ansiedade, que, muitas vezes, estão relacionados à falta de conhecimento e de capacitação para lidar com os acadêmicos com as mais diferentes necessidades especiais (ANJOS; ANDRADE; PEREIRA, 2009; MELO; PEREIRA, 2013).

Por outro lado, a formação de professores para educação inclusiva é um fato que deve ocorrer por meio de investimento na própria formação para que estes possam desenvolver e adquirir um novo modelo de prática pedagógica voltada para uma educação de qualidade.

É importante investir no espaço de formação de professores em seu próprio local de trabalho, por meio de cursos de capacitação, palestras e discussões que levem ao esclarecimento das principais dificuldades que os professores enfrentam em seu cotidiano de sala de aula. Além disso, é necessário que haja trocas de experiências positivas entre os professores que possam favorecer a construção de novos saberes pedagógicos (RODRIGUES; RODRIGUES, 2011; TOLEDO; VITALIANO, 2012).

Segundo Briant e Oliver (2012), também é preciso investir no processo de formação inicial e continuada dos professores, pois isto tem uma grande influência na capacidade destes em realizar seu trabalho com qualidade, possibilitando-lhes se sentirem mais seguros diante de algumas situações reais de seu cotidiano em sala de aula. Os mesmos autores afirmaram que a formação continuada é uma realidade para todos os professores, e não só apenas para aqueles professores que trabalham com acadêmicos com necessidades educacionais especiais. 
A inclusão de alunos com necessidades educativas especiais: um desafio para a universidade

Além da formação continuada, é necessário que os professores tenham um auxílio para desenvolver seu trabalho através de um apoio pedagógico especializado, e apresentem um domínio de alguns instrumentos que possam facilitar a evolução de suas práticas pedagógicas; isto ocorre por meio de palestras e treinamentos específicos (ANJOS, ANDRADE; PEREIRA, 2009; DE VITTA; DE VITTA; MONTEIRO, 2010).

Afinal, como afirma Figueiredo (2008), a formação inicial bem como a formação continuada de professores devem favorecer a inclusão de todos os acadêmicos, propiciando o acesso deles na universidade.

Silva (2009) reitera que a inclusão dos acadêmicos não depende só de uma boa prática e de uma excelente formação dos professores, mas deve ir além disso, deve incluir também materiais e recursos didático-pedagógicos adequados e adaptações nos currículos dos diferentes cursos superiores.

Com base nisso, Leite et al. (2011) afirmam que as adaptações curriculares são necessárias para atender às necessidades e aos interesses dos acadêmicos, principalmente aqueles que apresentam dificuldades específicas relacionadas às suas necessidades especiais.

Para que essas adaptações curriculares aconteçam nas instituições de ensino superior, primeiro precisa-se preparar um currículo comum para todos acadêmicos e, em seguida, devem ser realizadas algumas transformações em seu currículo voltadas para atender as necessidades educacionais especiais dos acadêmicos. Para tornar-se isso uma realidade, é necessário que a universidade reveja seus métodos, suas práticas, seu currículo e até as diferentes formas de metodologias e de avaliações do processo de ensino-aprendizagem. Através dessas mudanças, espera-se que o ambiente universitário seja capaz de oferecer respostas educativas aos acadêmicos, independente de suas necessidades ou do ritmo de suas aprendizagens; isso se transforma numa estratégia que contribui para a inclusão desses 
acadêmicos na universidade (CUNHA; CARRILHO 2005; SILVA, 2009; LEITE; BORELLI; MARTINS, 2013).

Além das adaptações no currículo, Moraes (2007) menciona que as instituições de ensino superior precisam também tornar seus ambientes mais acessíveis e adaptados para a inclusão de seus acadêmicos com necessidades educativas especiais, sendo que isso pode ocorrer por meio de algumas modificações e adaptações em sua estrutura física, para que possam eliminar assim quaisquer tipos de barreiras presentes no ensino de qualidade desses acadêmicos.

Nesse sentido, algumas adaptações realizadas nos aspectos das estruturas físicas se fazem necessárias por meio de projetos para promover a adequação dos espaços já construídos anteriormente, para facilitar o acesso em todos os espaços que envolvem banheiros adaptados com barra de apoio, elevadores, pisos antiderrapantes, portas mais largas, rampas, corrimões que devem ser instalados em ambos os lados dos degraus de escadas e rampas. Além disso, esses ambientes precisam estar sinalizados com símbolos que indicam o acesso a alguns serviços e também facilitam a locomoção desses acadêmicos (MORAES, 2007; MAIOLA; BOOS; FISCHER, 2008).

No entanto, conforme Siqueira e Santana (2010), a inclusão de acadêmicos com necessidades educacionais especiais na universidade não está apenas relacionada às adaptações no espaço físico, mas também envolve a questão da carência de materiais e de recursos didático-pedagógicos adequados para o processo de ensino-aprendizagem destes acadêmicos.

Ferroni e Gasparetto (2012) afirmam que o acesso desses acadêmicos nas instituições de ensino acadêmico deve ser garantido também por meio da utilização de recursos de tecnologia assistiva. Dessa forma, a tecnologia assistiva torna-se uma ferramenta essencial de apoio para inclusão de acadêmicos com deficiência, os quais inclusive destacam que a tecnologia assistiva constitui-se como um 
A inclusão de alunos com necessidades educativas especiais: um desafio para a universidade

dos recursos disponíveis mais importantes e que deve estar ao alcance dos professores na abordagem dos diferentes conteúdos.

Para Haiduke e Alcântara (2007), no entanto, esses recursos são equipamentos ou parte deles, produtos ou sistemas fabricados em série ou sob medida para que possam ser utilizados para aumentar, manter ou melhorar as capacidades funcionais dos acadêmicos com algum tipo de deficiência. Quase sempre, os acadêmicos com necessidades educativas especiais dependem de alguns instrumentos, materiais e equipamentos que devem ser construídos para suas necessidades; isto envolve alguns recursos pedagógicos adaptados que são muitos importantes para facilitar o processo de ensino e de aprendizagem dos conteúdos (BIDARRA; BOSCARIOLI; PERES, 2011).

A utilização desses recursos didático-pedagógicos deve ser adaptada conforme as necessidades educacionais especiais de cada acadêmico, as quais devem ser centradas também nas condições de aprendizagem desses acadêmicos (MIRANDA; GALVÃO FILHO, 2012).

Esses recursos podem ser simples ou tecnologias mais avançadas, tais como: adequações das bibliotecas para o acesso a livros em Braille e a adesão de livros gravados em áudio, Língua Brasileira de Sinais (LIBRAS), leitura labial para facilitar a comunicação. Ainda podem ser utilizados, cadeiras de rodas, muletas e bengalas para o auxílio dos portadores de necessidades especiais físicas (HAIDUKE; ALCÂNTARA, 2007; BASTABLE, 2010; SIQUEIRA; SANTANA, 2010; MIRANDA; GALVÃO FILHO, 2012).

Os autores Manzini (2005), Moraes (2007) apontaram que o ambiente de ensino acadêmico e a adaptação dos recursos pedagógicos podem oferecer a aprendizagem e favorecer a todos os acadêmicos com ou sem deficiência em um mesmo espaço e tempo.

Diante de todas essas medidas realizadas para a inclusão desses acadêmicos na universidade, Melo e Pereira (2013) corroboram que a educação inclusiva é tida como uma forma de retirada de todos os 
tipos de desafios presentes no ambiente universitário que, muitas vezes, impede a alguns acadêmicos a oportunidade de acesso a uma educação de qualidade, um direito que deve ser assegurado a todos os acadêmicos. Em virtude disso, a educação inclusiva pode ser considerada como uma perspectiva voltada para atender às dificuldades de aprendizagem de qualquer acadêmico inserido em sala de aula, inclusive a dos acadêmicos com necessidades educativas especiais, a quem devem ser assegurados os mesmos direitos em relação aos demais acadêmicos.

Para Martins (2008), a educação inclusiva é vista como uma perspectiva educacional que, muitas vezes, exige novas mudanças, desafiando assim as instituições de ensino superior a oferecer respostas educativas adequadas às necessidades de todos os acadêmicos.

Diante disso, Miranda e Galvão Filho (2012) põem em debate que a educação inclusiva não se refere apenas a algumas modificações que devem ser realizadas na estrutura física das instituições de ensino, mas sim nos métodos e nas formas de ensinar e avaliar, mesmo quando os acadêmicos com deficiência são aceitos. Por outro lado, a educação inclusiva é uma forma de reconhecer as diferenças e adequar algumas condições para que o acesso dos acadêmicos com necessidades educativas especiais não se constitua como um desafio ou um impedimento enfrentado por estes em sua formação.

Nesse contexto, considera-se importante o que Maiola, Boos e Fischer (2008) afirmam ao dizer que a inclusão na universidade consiste na qualidade da formação acadêmica, que é de fundamental importância para o próprio acadêmico em relação a sua perspectiva pessoal e profissional. Portanto a universidade tem que ter consciência dessa diversidade e deve promover a inclusão de todos para favorecer a educação de qualidade para qualquer acadêmico. 
A inclusão de alunos com necessidades educativas especiais: um desafio para a universidade

\section{CONSIDERAÇÕES FINAIS}

A partir da pesquisa realizada sobre o processo de inclusão de acadêmicos com necessidades educacionais especiais no ambiente universitário, observou-se que esses acadêmicos enfrentam diversos desafios, dentre os quais podemos citar: a presença de barreiras arquitetônicas, a falta ou a inadequação de recursos didático-pedagógicos indispensáveis para atender as necessidades educacionais e o despreparo dos professores em lidar com a inclusão desses acadêmicos. A maioria dos docentes apresenta dificuldades em promover a inclusão de acadêmicos com necessidades educacionais especiais em sala de aula, devido a uma formação inicial e continuada desvinculada da realidade social desses alunos.

Da mesma forma que houve uma grande evolução histórica até se chegar à formulação da educação inclusiva, a sociedade também deve descobrir que a universidade é um espaço plural e diverso, lugar não apenas de iguais, mas também de diferentes. E que todos os acadêmicos, com ou sem deficiência, devem estar incluídos nas políticas e práticas educacionais. Também se deve voltar a atenção para a questão da adaptação curricular considerando o desenvolvimento de novas habilidades e novas competências relacionadas ao processo de ensino-aprendizagem e ainda para a formação do professor, que deve envolver toda sua experiência e conhecimento no sentido de proporcionar ao aluno com necessidade educativa especial o máximo de estímulos, possibilidades de vivências e ampliação de sua aprendizagem.

Nesse sentido, a construção de uma educação inclusiva de qualidade no ambiente universitário exige mudanças e adaptações de todos os sujeitos envolvidos no processo educacional: professores, alunos, familiares e a própria sociedade. De modo geral, cabe aos envolvidos nessa prática inclusiva voltada para atender a diversidade, promover 
ações de aceitação, respeito, diálogo, cooperação, flexibilização tanto na adaptação curricular quanto numa formação docente, com uma abordagem mais ampla e contínua. Além disso, deve-se investir na construção de um espaço universitário com ambientes adaptados, ferramentas e recursos didáticos que rompam com as dificuldades inerentes ao processo de ensino-aprendizagem desses acadêmicos.

Diante desses desafios enfrentados pelos acadêmicos ao iniciarem a vida na universidade, onde eles têm assegurado o direito ao acesso de uma educação de qualidade, evidencia-se a necessidade de aperfeiçoamento em todos os prismas da universidade, partindo das estruturas físicas, da elaboração de disciplinas curriculares direcionadas, do aperfeiçoamento da formação curricular dos professores e da inserção de tecnologias assistivas.

A inclusão vai além do que se vê ou se toca, a inclusão deve vir de dentro de cada um, pois ser diferente não é o problema, o problema é ser tratado de diferente. Porém, na realidade, essa frase é uma utopia, visto que, quando analisado de maneira crítica, percebe-se que o processo de inclusão não se refere somente à esfera atitudinal do aluno, mas também às condições oferecidas pela universidade para promover esse processo, seja por meio de adaptações nas estruturas físicas ou por meio de atendimento educacional especializado. Nesse sentido, não importa só querer, é fundamental saber fazer. Saber trabalhar com a diversidade, respeitando as condições e as limitações dos alunos, é minimamente uma condição para garantir não só o acesso, mas também a permanência desses alunos, com sucesso, no ensino superior.

\section{REFERÊNCIAS}

ANJOS, H. P.; ANDRADE, E. P.; PEREIRA, M. R. A inclusão escolar do ponto de vista dos professores: o processo de constituição de um discurso. Revista Brasileira de Educação, v. 14, n. 40, p. 116-29, jan./abr. 2009. 
A inclusão de alunos com necessidades educativas especiais: um desafio para a universidade

BASTABLE, S. O enfermeiro como educador: princípios de ensino aprendizagem para prática de enfermagem. 3. ed. Porto Alegre, RS: Artmed, 2010.

BIDARRA, J.; BOSCARIOLI, C.; PERES, S. M. Software xlupa- um ampliador de tela para auxílio na educação de alunos com com baixa visão. Revista Brasileira de Educação Especial, Marília, SP, v. 17, n. 1, p. 151-72, 2011.

BRASIL. Ministério da Educação (MEC), Instituto Nacional de Estudos e Pesquisas Educacionais (INEP). Censo de Educação Superior. Brasília: MEC/ INEP, 2012.

. Decreto n. 5.296, de 2 de dezembro de 2004. Regulamenta as Leis n. 10.048 , de 8 de novembro de 2000, que dá prioridade de atendimento ás pessoas com deficiência, e a Lei n. 10.098, de 19 de dezembro de 2000, que estabelece normas gerais e critérios básicos para a promoção da acessibilidade para as pessoas portadoras de deficiência ou mobilidade reduzida e outras providências. Diário Oficial da União, Brasília, 3 dez 2004, Seção 1, p. 5.

. Lei n. 9.394, de 20 de dezembro de 1996. Fixa a Lei das Diretrizes e Bases da Educação Nacional Brasileira. Diário Oficial da União. Disponível em: <http://www.ffclrp.usp.br/graduacoes/estagio/legislacao/lein9394.pdf>. Acesso em: 15 mar. 2016.

BRIANT, M. E. P.; OLIVER, F. C. Inclusão de crianças com deficiência na escola regular numa região do município de São Paulo: conhecendo estratégias e ações. Revista Brasileira de Educação Especial, Marília, SP, v. 18, n. 1, p. 141-54, 2012.

CUNHA, S. M.; CARRILHO, D M. O processo de adaptação ao ensino superior e o redimento acadêmico. Psicologia Escolar e Educacional, v. 9, n. 2, p. 215-24, 2005.

DE VITTA, F. C. F.; DE VITTA, A.; MONTEIRO, A. S. R. Percepção de professores de educação infantil sobre a inclusão da criança com deficiência. Revista Brasileira de Educação Especial, Marília, SP, v. 16, n. 3, p. 415-28, 2010.

DUARTE, E. R. et al. Estudo de caso sobre a inclusão de alunos com deficiência no ensino superior. Revista Brasileira de Educação Especial, Marília, SP, v. 19, n. 2, p. 289-300, abr./jun. 2013.

FERRONI, M. C.; GASPARETTO, M. E. R. Escolares com baixa visão: percepção sobre as dificuldades visuais, opinião sobre as relações com comunidade escolar e o uso de recursos de tecnologia assistiva nas atividades cotidianas. Revista Brasileira de Educação Especial, Marília, SP, v.18, n. 2, p. 301-18, 2012. 
FIGUEIREDO, R. V. A formação de professores para inclusão dos alunos no espaço pedagógico da diversidade. 1. ed. Petrópolis, RJ: Vozes, 2008. v. 1, p. 141-5.

FRANÇA, I. S. X.; PAGLIUCA, L. M.; BAPTISTA, R. S. Política de inclusão do portador de deficiência: possibilidades e limites. Acta Paulista de Enfermagem, São Paulo, v. 21, n. 1, p. 112-6, 2008.

GASPARETTO, M. E. R. F. et al. Uso de recursos de tecnologia assistiva na educação municipal, estadual e federal tecnológica. In: BRASIL. Subsecretaria Nacional de Promoção dos Direitos da Pessoa com Deficiência. Comitê de Ajudas Técnicas (Org.). Tecnologia Assistiva. Brasília: Corde, 2009. p. 41-58.

GIROTO, C. R. M.; CASTRO, R. M. A formação de professores para a educação inclusiva: alguns aspectos de um trabalho colaborativo entre pesquisadores e professores da Educação Infantil. Revista de Educação Especial, Santa Maria, RS, v. 24, n. 41, p. 441-51, 2011.

HAIDUKE, I. F.; ALCÂNTARA, P. R. Inclusão de acadêmicos com necessidades especiais na universidade: a influência do GT-AUNE no acesso ao ensino aprendizagem. 2007. Disponível em: <http://www.pucpr.br/eventos/ educere/educere2007/anaisEvento/arquivos/Cl-410-09.pdf>. Acesso em: 15 mar. 2016.

INSTITUTO BRASILEIRO DE GEOGRAFIA E ESTATÍ́sTICA (IBGE). Censo 2010. Rio de Janeiro, 2010.

LEÃO, A. M. C. O processo de inclusão: a formação do professor e sua expectativa quanto ao desempenho acadêmico do aluno surdo. 2004. 131 f. Dissertação (Mestrado em Educação Especial) - Universidade Federal de São Carlos (UFSCar), São Carlos, SP, 2004.

LEÃO, A. M. C.; COSTA, M. P. R. Inclusão: expectativa do professor quanto ao desempenho acadêmico do aluno surdo. Revista Brasileira de Estudos Pedagógicos, Brasília, v. 86, n. 213/214, p. 86-100, 2005.

LEITE, L.P. et al. A adequação curricular como facilitadora da educação inclusiva. Psicologia da Educação, São Paulo, n. 32, p. 89-111, 1o sem. 2011. LEITE, L. P.; BORELLI, L. M.; MARTINS, S. E. S. O currículo e deficiência: análise de publicações brasileira no cenário da educação. Educação em Revista, Belo Horizonte, v. 29, n. 1, p. 63-92, 2013. 
A inclusão de alunos com necessidades educativas especiais: um desafio para a universidade

LOPES, E.; MARQUEZINE, M. C. Sala de recursos no processo de inclusão do aluno com deficiência intelectual na percepção dos profess ores. Revista Brasileira de Educação Especial, Marília, SP, v. 18, n. 3, p. 487-506, 2012.

MAIOLA, C. S.; BOOS, F.; FISCHER, J. Inclusão na universidade sob a ótica dos acadêmicos com necessidades especiais: possibilidades e desafios. Ponto de Vista, Florianópolis, SC, n. 10, p. 79-93, 2008.

MANZINI, E. J. Tecnologia assistiva para educação: recursos pedagógicos adaptados. 1. ed. Brasília: MEC/SEESP, 2005.

MARTINS, L. A. R. Educação e diversidade: um breve preâmbulo. João Pessoa, PB: Ideia, 2008.

MASINI, E. F. S. A inclusão escolar do aluno com deficiência visual. Rio de Janeiro: Cultura Médica; Guanabara Koogan, 2010. p. 427-44.

MELO, F. R. L.; PEREIRA, A. P. M. Inclusão escolar do aluno com deficiência física: visão dos professores acerca da colaboração do fisioterapeuta. Revista Brasileira de Educação Especial, Marília, SP, v. 19, n. 1, p. 93-106, 2013.

MENDES, E. C. Breve história da educação especial no Brasil. Revista Educação e Pedagogia, São Carlos, SP, v. 22, n. 57, p. 93-109, 2010.

MICHELS, M. H. O que há de novo na formação de professores para a Educação Especial? Revista de Educação Especial, Santa Maria, RS, v. 24, n. 40, p. 219-32, 2011.

MIRANDA, T. G.; GALVÃO FILHO, T. A. O professor e a educação inclusiva: formação, práticas e lugares. Salvador: EDUFBA, 2012.

MONTEIRO, A. P. H.; MANZINI, E. J. Mudanças de concepções de professores do ensino fundamental que receberam alunos com deficiência em sua classe. Revista Brasileira de Educação Especial, Marília, SP, v. 14, n. 1, p. 35-52, 2008.

MORAES, M. G. Acessibilidade e inclusão social em escolas. 2007. Trabalho de Conclusão de Curso (Graduação em Pedagogia) - Faculdade de Ciências, Universidade Estadual Paulista (UNESP), Bauru, SP, 2007.

NASCIMENTO, R. P. Preparando professores para promover a inclusão de alunos com necessidades educacionais especiais. Londrina, PR, 2009. Disponível em: <http://www.diaadiaeducacao.pr.gov.br/portals/pde/ arquivos/2496-8.pdf>. Acesso em: 17 mar. 2016 
PACHECO, R. V.; COSTAS, F. A. T. O processo de inclusão de acadêmicos com necessidades educacionais especiais na Universidade Federal de Santa Maria. Revista Educação Especial, Santa Maria, RS, n. 27, p. 151-67, 2006. Disponível em: <http://www.ufsm.br/revistaeducacaoespecial>. Acesso em: 14 mar. 2016.

PERINI, T. I. O processo de inclusão no Ensino Superior em Goiás: a visão dos excluídos. 2006. 121f. Dissertação (Mestrado em Educação) - Faculdade de Educação, Universidade Católica de Goiás, Goiânia, 2006.

REBOUÇAS, C. B. A. et al. Pessoa com deficiência física e sensorial: percepção de alunos da graduação em enfermagem. Acta Paulista de Enfermagem, São Paulo, v. 24, n. 1, p. 80-6, 2011.

RÉUS, N. R. M.; CAVALARL, N. A educação inclusiva no Brasil. Caderno Multidisciplinar de Pós-graduação da UCP, Pitanga, PR, v. 1, n. 2, p. 202-15, 2010.

ROCHA, T. B.; MIRANDA, T. G. Acesso e permanêcia do aluno com deficiência na instituição de ensino superior. Revista Educação Especial, Santa Maria, RS, v. 22, n. 34, p. 197-212, 2009.

RODRIGUES, D.; RODRIGUES, L. L. Formação de professores e inclusão: como se reformam os reformadores? Educar em Revista, Curitiba, n. 41, p. 41-60, 2011.

RODRIGUES, O. M. P. R.; MARANHE, E. A. (Org.). Educação especial: história, etiologia, conceitos e legislação vigente. Bauru, SP: MEC/FC/SEE, 2008.

SILVA, L. M. Educação inclusiva e formação de professores. 2009. Trabalho de Conclusão de Curso (Especialização Lato Sensu a distância em Educação Profissional Tecnológica Inclusiva) - Instituto Federal de Educação, Ciência e Tecnologia do Estado de Mato Grosso, Campus Cuiabá, MT, 2009.

SIQUEIRA, I. M.; SANTANA, C. S. Propostas de acessibilidade para a inclusão de pessoas com deficiências no ensino superior. Revista Brasileira de Educação Especial, Marília, SP, v. 16, n. 1, p. 127-36, jan./abr. 2010.

TOLEDO, E. H.; VITALIANO, C. R. Formação de professores por meio de pesquisa colaborativa com vistas à inclusão de alunos com deficiência intelectual. Revista Brasileira de Educação Especial, Marília, SP, v. 18, n. 2, p. 319-36, 2012. 
A inclusão de alunos com necessidades educativas especiais: um desafio para a universidade

VITALIANO, C. R. Análise da necessidade de preparação pedagógica de professores de cursos de licenciatura para inclusão de alunos com necessidades educacionais especiais. Revista Brasileira de Educação Especial, Marília, SP, v. 13, n. 3, p. 399-414, set./dez. 2007. 
